Resumen: El debate sobre la ineficacia del concepto de clase como categoría de análisis sociológico, mencionado en los escritos de Ray E. Pahl en Divisiones del Trabajo y de Jan Pakulski y Malcom Waters The Death of Class; contribuyeron a acrecentar las críticas profundizando de forma negativa la teoría de la distinción de Bourdieu (2010), aludiendo a que se fundamenta en una relación entre clase, formación del gusto y consumo, superada por la fragmentación social y la globalización. En este sentido destacamos Coulangeon and Lemel en Social Status and Cultural Consumption del año 2010. Este escrito contrapone que, aunque en sociedades sumamente desarrolladas y democráticas, se observan consumos individualizados y omnivoristas, éstos se desarrollan a partir de diferenciaciones simbólicas, grupos de referencia, ocupaciones y niveles de renta. Por lo que la pertenencia a una clase social resultará un factor clave para la compra de moda. Sin embargo, respecto al habitus, que sea sobreestimado como un inconsciente de clase, aun siendo una estructura estructurante, induce a pensar que las prácticas de consumo son poco inteligibles. De ahí la relevancia de considerarlo como conciencia de clase.

Palabras clave: sociología, consumo, estatus, distinción, omnívoro, clase social, habitus, conciencia de clase, teoría de la distinción, sociedades.

[Resúmenes en inglés y portugués en las páginas 115-116]

(1) Licenciado en Ciencias Políticas y Sociología por la Universidad Nacional de Educación a Distancia UNED 2004. Doctor en Sociología por la Universidad Autónoma de Barcelona 2010. Investigador independiente de la relación entre consumo y estructura social en las sociedades posmodernas. Artículos publicados "La fascinación por la moda como expresión de libertad" en la Revista RES, No 16 (2011) y "Moda, Gènere i Consum" en la Revista Catalana de Sociología RCS, No 29 (2014). Miembro invitado del grupo de investigación CERHUM en 2012 en la Universidad Autónoma de Barcelona. 


\section{Moda, clase social y habitus}

El individuo, dominado por los intereses limitados y mezquinos de sus de seos, no es libre, puesto que no se determina por la universalidad y la racionalidad esencial de su voluntad, ni es libre en relación al mundo exterior, pues el deseo está esencialmente determinado por las cosas y se relaciona con ellas (Hegel, 1997, p. 79).

Si es necesario recordar también las condiciones sociales de posibilidad de la representación dominante de la manera legítima de abordar las obras de arte -es decir, las condiciones sociales de producción del ideal de un gusto "desinteresado" y de los "hombres de gusto" capaces de obedecer en su percepción o su producción de la obra de arte a los cánones de una "estética pura"-, es porque la definición completa del gus to en su función social de signo de distinción excluye precisamente la conciencia de esas condiciones (Bourdieu, 2010, p. 68).

\section{Introducción}

“...romper con la representación realista de la clase como grupo bien delimitado" (Bourdieu, 2000, p. 58) supuso, hace ya cuatro décadas, hallar un punto equidistante entre quienes creían que la realidad era compacta y bien recortada y quienes presumían que cualquier persona podía ser de cualquier parte. El esfuerzo por intentar superar la yuxtaposición de las fracciones constitutivas de una sociedad estratificada puede enmarcarse dentro de dos procesos que, a juicio de Caínzos (1990), surgieron simultáneos pero contradictorios en los años setenta entorno al análisis de clase: uno a favor, de planteamientos marxistas aunque también weberianos, como es el caso que nos ocupa, capaz de aportar nuevos modelos teóricos y analíticos de alto grado conceptual, flexibilidad y sofisticación; y otro en contra, que no sólo cuestionaba su plausibilidad teórica sino también empírica, y que atacaba la matriz de los supuestos que constituyen su presunto fundamento. Desde entonces, aunque el marketing se ha reorientado, cada vez más, a fabricar experiencias y no tanto productos, las referencias a Bourdieu no han dejado de ser obligatorias para los análisis de consumo. Siendo esta la razón principal que nos induce a considerar que los factores sociales, como el grupo de referencia, y los factores emocionales, como la diferenciación simbólica, siguen interrelacionados con los factores económicos, como el nivel de renta y la ocupación, en un tema como es la moda, cuyo significado es mucho más que la ropa que vestimos ${ }^{1}$. Es decir, si nos alejamos de los enfoques posmodernos y sus conclusiones, así como del aserto que asegura que la sociedad y la identidad han sido sustituidas por la socialidad y la identificación ${ }^{2}$, cabe preguntarse si la diseminación del sentido, la dispersión de los signos y la dificultad para establecer códigos estables y compartidos, contraviene, de algún modo, a que la clase social prevalezca como factor clave para la compra de cualquier producto. Y más, si este retiene un elevado componente aspiracional. Efectivamente, admitir que los estilos de vida continúan expresando jerarquías 
de orden social, implica asumir que las críticas a la teoría de la distinción carecen, hasta el momento, de objeto. Si más no porque, apreciándose en ellas una cierta confusión entre gusto y consumo, acaban por obviar que éstas son dos realidades independientes entre sí que necesitan de un catalizador, como es la clase social, para poder ser explicadas. Sobre todo, desde que en el siglo XVIII la atribución de estatus empezará a basarse, cada vez más, en el logro económico. He aquí porqué las prácticas de consumo individualista u omnivoristas ${ }^{3}$, como resultado de un supuesto declive de la estratificación cultural, sólo pueden ser consideradas como nuevos indicadores con los que continuar expresando pertenencia o aspiración a un grupo, subgrupo o clase social.

Así, dado que el objetivo de este escrito no es otro que reflexionar sobre la vigencia de la clase social como categoría de análisis a partir de una línea argumental que homologa clase y estatus en función de un habitus, primero comenzaremos revalorizando la definición de dicho concepto elaborada por Bourdieu para, seguidamente, señalar cuál es su relación con las prácticas de consumo de moda. A continuación, ponderaremos si los gustos de los diferentes grupos sociales se mantienen diferenciados y si por habitus puede entenderse conciencia de clase. Por último, finalizamos con unas sucintas apreciaciones.

\section{La clase como categoría de análisis}

Aunque el objetivo de Karl Marx fue ambicioso: transformar el mundo, su análisis global de la sociedad capitalista quedó falto de una definición de su concepto principal clase social. Por ello, más allá de las lógicas limitaciones de su gran síntesis conocida como materialismo histórico, cuando escribió el siguiente comentario acerca del pro letariado: "Así, pues, esta masa es ya una clase con respecto al capital, pero aún no es una clase para sî" (Marx, 2010, p. 90), dejó abierto un debate académico, aún no clausurado, sobre lo que debía de entenderse por clase: si una clase en sí, materialmente objetivada, o una clase para $s i$, subjetivamente consciente. Es decir, si la clase es lo que existe como una realidad histórica o lo que ha adquirido conciencia de su identidad y capacidad de actuar.

Un disenso que acabaría originando dos aproximaciones distintas al estudio de las clases entre quienes persiguen una investigación empírica de la estructura de clase y quienes consideran la conciencia y la estructura como facetas de un mismo fenómeno (Crompton, 1997). En este sentido, mientras a la primera aproximación se le reconocen contigüidades con el estructuralismo marxista y el funcionalismo estructural representado por analistas como Bendix y Lipset, Dahrendorf, Lockwood, Goldthorpe o Wright, de gran calado en Norteamérica e Inglaterra, a la segunda aproximación se le identifica con la perspectiva marxista humanista y con investigadores de la talla de Bauman, Bottomore o el mismo E.P. Thompson. Quien, en defensa de la no separación entre acción y estructura funde las concepciones de clase en sí y clase para sí en una categoría global de experiencia que le induce a revelar que:

Por clase, entiendo un fenómeno histórico que unifica una serie de sucesos dispares y aparentemente desconectados, tanto por lo que se refiere a la mate- 
ria prima de la experiencia, como a la conciencia. Y subrayó que se trata de un fenómeno histórico. No veo la clase como una estructura, ni siquiera como una categoría, sino como algo que tiene lugar de hecho en las relaciones humanas (1989, p. XIII).

Es decir, el historiador inglés, alejado de un estructuralismo objetivista extremo, revalorizará, al igual que Bourdieu (2000), la subjetividad en la definición de la clase social. Por lo que, según ambos autores, una clase nunca podrá definirse ni previa ni exclusivamente por determinaciones objetivas. Una opinión cercana a la de Merleau-Ponty cuando éste concluye que "La clase, en efecto, no es ni constatada, ni decretada" (1975, p. 454). Dicho esto, y precisando que para Bourdieu

Una clase social nunca se define únicamente por su situación y por su posición en una estructura social, es decir por las relaciones que objetivamente mantiene con las demás clases; [pues] también debe muchas de sus propiedades al hecho de que los individuos que la componen entran deliberada y objetivamente en relaciones simbólicas que, al expresar las diferencias de situación y de posición según una lógica sistemática, tienden a transmutarse en distinciones significantes (2002b, p. 131).

Es obvio sospechar que en el pensamiento más profundo del autor francés resta el exhortar a que "Se puede y debe ir más allá de la oposición entre la visión que indistintamente podemos etiquetar como realista, objetivista o estructuralista por un lado, y la visión constructivista, subjetivista o espontaneista por otro" (2001, p. 118). De modo que su concepto de clase sólo puede entenderse como un espacio de posibles debido: primero, a procesos de clasificación; segundo, a la posición ocupada; y tercero, a la trayectoria realizada para alcanzar dicha posición. Pudiéndose movilizar tal espacio de posibles sólo bajo condiciones favorables y por medio de actos de reconocimiento externos e internos. De ahí que la validez de su inflexión teórica estriba, precisamente, en aquello que se le reprocha desde las posiciones marxistas clásicas. Y es que para la construcción teórica de una clase, no basta la separación de un grupo ocupacional. Lo que entraña no poder designar a las clases por un nombre de profesión porque enmascaran otras características auxiliares como el género, la etnia, el origen social, la cultura, etc. Así, aunque su estrategia para investigar la estructura de clase se asemeja a la estrategia de la sociología tradicional, es decir, identifica primero los factores que producen la clase y luego los vincula a las actitudes y predisposiciones, o la conciencia, se aparta de ella en tanto pone énfasis en resaltar que, siendo el espacio social un espacio pluri-dimensional, su naturaleza es diversa y socialmente construida. De este modo, de "su conceptualización de clase extremadamente general y que va más allá de las de Marx y Weber” (Crompton, 1997, p. 213), cabe inferir que los estilos de vida nunca van a poder ser tratados empírica y analíticamente separados. Pues, siendo estos la máxima expresión de estatus, remiten a una estructura de clases determinada por las relaciones sociales que surgen, en una vida económica, de las interacciones con el mercado de trabajo y las unidades de producción. De ahí que podamos sostener que Bourdieu (2000), a través del habitus como concepto mediador entre la clase social y las prácticas de 
consumo, lejos de ahondar en la separación entre lo social y lo económico, tal como hacen los enfoques postmodernos, lo que propone es incorporar la producción a la explicación sociológica (Alonso, 2005).

\section{La clase y el consumo de moda}

Ciertamente, siendo el estatus uno los dos ejes fundamentales sobre los que se articulan las diferencias en el vestir, el otro es el género, que los objetos valiosos sean metonímicos de los sistemas de poder y prosperidad obliga a reconocer que sólo los indumentos de las élites acumulan potencialidad suficiente como para despertar deseos de admiración y apropiación entre las masas. Una propensión que, lejos de manifestarse únicamente en sociedades modernas, sólo a comienzos del siglo XX, en pleno auge industrial, es cuando se relativiza con la aparición de nuevos grupos sociales, en su mayoría estudiantes y obreros. Un protagonismo de los estamentos situados en la base de la pirámide social sobre los situados en la cima que se materializa, por un lado, gracias al aumento del poder adquisitivo, y por otro, a la ampliación de una oferta en continua renovación. Dos dinámicas interrelacionadas que, desde entonces, han obligado a reflexionar sobre la capacidad de respuesta de un sistema necesitado de adaptaciones periódicas a las múltiples reconfiguraciones del espíritu capitalista. De suerte que, el ejemplo más cercano lo tenemos en la década de los ochenta del siglo XX. Una época alejada de la bohemia juvenil de los años sesenta en la que eclosiona una nueva clase profesional ligada a la intermediación simbólica y financiera, los yuppies, en un período de coyuntura político-económica globalizada y desmaterializada a la que el sistema moda responde con nuevas técnicas de producción y distribución, segmentación de los mercados, y la preponderancia de los medios de comunicación. Una situación aprovechada por financieros y magnates para invertir en la que, en opinión de muchos, había de constituir la fase de mayor renovación y democratización del lujo en la historia pero que, sospechosamente, sólo acabó por motivar que ciudadanos de países y culturas diferentes vistieran de forma parecida. Muchos de ellos con imitaciones, copias y falsificaciones de grandes firmas y marcas. En efecto, dicho contexto, de enorme potencial económico, no sólo modificó la manera de consumir sino que alteró las posibilidades y las formas de ser ciudadano en países desarrollados. Pues, que por un lado, la racionalización, el control y la planificación garantizará el consumo de bienes privados estandarizados y masivos $^{4}$, y que por otro, los efectos económicos de los procesos de producción elevan el poder adquisitivo de amplios sectores de la ciudadanía, condujo, de forma general, a un diagnóstico sobre el consumo tan mitificado como positivo que hizo que los valores y comportamientos de unos pocos se confundieran con los de la mayoría. Haciendo creer, no se sabe bien si por intereses comerciales o por miopía analítica, que las clases populares habían igualado a las élites en su forma de vestir. Sin embargo, hasta el momento, nadie ha podido confirmar que en sociedades post industrializadas el fondo de armario de quien es miembro de un grupo social cualificado y cosmopolita sea el mismo de quien forma parte de un grupo excluido o con condiciones de vida y trabajo precarizadas. Pues, si a partir de una revisión documentada se hace difícil corroborarlo, ya que aunque la fotografía sea 
un espejo con memoria dicha memoria puede ser imaginada, pensemos si no en cómo lo publicitado es siempre un estereotipo de lo que se debería ser y no de lo que realmente se es, no menos fácil resulta a través de teorías ${ }^{5}$, como la de Bourdieu, que han probado que los gustos se resisten a los cambios. Es decir, vestirse a la moda no sólo implica contar con recursos económicos sino aceptar cambios estéticos asociados a valores que un individuo, como miembro integrado en un grupo, ha de ser capaz de encontrar significado. Y es que, al igual que la legibilidad de una obra de arte, la legibilidad de un indumento depende de la distancia entre el nivel de emisión, definido como el grado de complejidad intrínseco del código exigido por el indumento, y el nivel de recepción, definido como el grado en el cual los individuos dominan el código social, él mismo más o menos adecuado al código exigido por dicho indumento ${ }^{6}$. De ahí la dificultad de asentir, incluso teniendo vívida la revolución producida en el mundo de la producción y los consumos culturales, que los estilos de vida sean hibridaciones de gustos alejados de cualquier estructura o unidad social. Pues, por muchas posibilidades de elección que el mercado pueda brindar, siempre aparecen restricciones y auto-restric ciones basadas en la necesidad de no extralimitar los acuerdos simbólicos que regulan la vida en colectividad. Una inferencia con la que no se pretende contravenir la existencia de habitus transculturales y transclasistas (Beriain, 1996) procedentes de la cultura globalizada que homogeniza gustos y prácticas sociales, sino tan sólo acentuar que los diferentes habitus inscritos en tradiciones culturales específicas y con posicionamientos de clase determinados siguen presentes y mantienen, en unos campos más que en otros, una preponderancia sobre la acción. Siendo este el motivo por el que creemos poder afirmar que la teoría que relaciona niveles sociales con gustos y consumos, la teoría de la distinción, no niega los comportamientos omnivoristas u individualistas del consumidor en sociedades postindustriales. Lo que niega, es la desaparición de las jerarquías culturales a pesar de la industrialización cultural y la reproducibilidad de los objetos a la que alude Benjamin (2004). Pues, ni el arte, ni la filosofía, ni la política, ni la religión ${ }^{7} \mathrm{o}$ la bohemia han podido nunca, ni tampoco lo han pretendido, abolir una determinada jerarquía de estatus, sino que han tratado de instituir nuevas clases de jerarquía basadas en valores críticos con los de la mayoría De Botton (2004). Siendo precisamente en momentos como en los actuales, en los que el orden establecido es fuertemente cuestionado, cuando otras formas de participación, entiéndase consumo privado, acaban por emerger o intensificarse como instrumentos de reubicación social. De ahí que el consumo desenfrenado contra la desazón y la incerteza revele, más allá de la desarticulación de las edades y ciclos de vida del fordismo, hasta qué punto la clase y el estatus son indisociables. Pues, lo que emerge, cuando no se puede aspirar a mejorar las condiciones de vida, es la voluntad de conservar recursos, libertad, espacio, comodidad y tiempo, así como atenciones y deferencias. Una propensión en la que la imitación y la emulación sirven como estrategias para expresar tomas de posición en un campo determinado.

En este sentido, una última consideración, que el bienestar económico y social haya favorecido el aumento de los niveles de consumo, y con ello, la configuración de una visión directamente lineal y evolucionista de la economía, implica tener que asumir por un lado, que la vida social de muchos ciudadanos puede haberse ampliado, y por otro, que la autopercepción respecto a su posición en la estructura social haya cambiado. De lo que se desprende una posible variación en sus actitudes hacia la moda y su forma de vestir ${ }^{8}$. Sin 
embargo, dado que los indumentos son unos objetos que retienen un alto grado de vinculación con el cuerpo, la persona y la personalidad, difícilmente se puede admitir que un consumo intensivo como el desarrollado en las últimas tres décadas, más cuantitativo que cualitativo, signifique, a día de hoy, una convergencia de gustos y/o estatus entre fracciones y clases sociales, tal como parece que se intenta abordar desde perspectivas posmodernas. $\mathrm{O}$ ¿acaso las élites han desistido en su intento de diferenciarse a través de estrategias de acopio de objetos valiosos? Es más, ¿no han continuado incrementándose los beneficios de las empresas de lujo en tiempos de crisis?

\section{La clase como base social del gusto}

Efectivamente, la represión que ejerce la estética reflexiva sobre todo aquello que se considera fácil de hacer, fácil de pensar y/o fácil de conseguir, se puede contrastar en uno de los análisis sociológicos que, habiéndose revelado indispensable para la comprensión del consumo cultural moderno, ha acabado por ampliar el reconocimiento académico de su autor. Nos referimos a La Distinción de Bourdieu (1991). Una obra en la que se procede a reconfigurar el espacio estético del gusto apoyándose críticamente en la estética idealista kantiana. Es decir, oponiendo al gusto como pura capacidad fenomenológica un gusto como capacidad cultural o estética realmente existente, producto de socializaciones diferentes, de capitales culturales diferentes, y de posicio nes dentro de la estructura social diferentes, que obliga a reconocer estilos de vida diferenciados basados en: primero, un sentido de la distinción y un ethos de la soltura como relación segura con el mundo y con el yo, propio de la gran burguesía; segundo, un sentido de la restricción por pretensión y voluntarismo rigorista por la formación, propio de la pequeña y de la burguesía media; y tercero, una elección determinada por lo necesario funcional y el gusto práctico-pragmático, propio de la clase obrera. De modo que, comenzando por la gran burguesía, dado que por estilización de la vida se entiende una afirmación de poder sobre la necesidad dominada, es lógico pensar que sólo los individuos que logren un cierto distanciamiento hacia la vida y las obligaciones materiales van a poder "hacer de su arte de vivir una de las bellas artes" (Bourdieu, 1991, p. 55). Sólo las clases altas y los artistas van a poder ser asignados como grupos capaces de desarrollar un "gusto puro articulado entorno a un posicionamiento estético completamente abstracto sobre el simbolismo de los bello" (Beriain, 1996, p. 374). Y, sin embargo, dado que ello es un ideal, la práctica evidencia que incluso en el gusto dominante existen variaciones entre fracciones de burguesía propietaria, con predominio de capital económico, y burguesía intelectual, con predominio de capital cultural. Por lo que aunque la tendencia de la gran burguesía sea la de experimentar una cotidianidad distante, es decir no dóxica, sí que debido a la diferente composición y volumen de capitales experimenta variantes de ortodoxia y heterodoxia. En este sentido ${ }^{9}$, basta recordar que para Weber (1984), a diferencia de Marx (2010), la clase basada en condiciones de vida material es sólo una de las formas de estratificación social. Pues existen otras, como el estatus, además del poder, que unido al honor y al prestigio también puede ser fuente principal de regulación del derecho a recompensa. Una apreciación que Baltzell (2009), en 
un análisis posterior de la formación de clases altas en América, utilizará para diferenciar el concepto de élite dimensión de poder de clase alta dimensión de prestigio, definiendo a la primera como un grupo de individuos con éxito profesional independientemente de su origen social, posición familiar o raza, y a la segunda, como un grupos de familias cuyos miembros son descendientes de una élite que han crecido juntos, son amigos y se casan entre ellos. Siendo este el motivo por el que mantienen un estilo de vida peculiar y comparten un tipo primario de solidaridad de grupo que les sitúa aparte del resto de la población. De ahí que se pueda advertir en la definición de clase alta tres componentes incorporados: a saber, descendientes, amigos y estilo de vida, que delatan una posibilidad de conciencia de grupo o clase con la que autodenominarse alta sociedad. Una observación que nos remite a Giner cuando subraya que dicha clase siempre aparece como "la más hábil en crear círculos cerrados de interacción y mantenimiento de la desigualdad y privilegio que tan favorablemente le beneficia" (1993, p. 143). Así, como la que tiende en mayor grado al refinamiento, aunque no siempre a la originalidad.

En las últimas décadas, las clases altas y las élites, es decir, los miembros de las antiguas familias burguesas y los individuos que ocupan posiciones de autoridad en las principales corporaciones, han mantenido una relación cada vez más intensa derivada del aprovechamiento mutuo de los mercados globales. Circunstancia que ha influido en redefinir las clases altas como un grupo minoritario de individuos que no solo son ricos sino que tienen poder y capacidad para transmitirlo a sus futuras generaciones Giddens (2009). Un juicio que se sustenta en análisis que concluyen que la redistribución de la riqueza y el poder siguen produciéndose, casi en exclusiva, entre familias de vieja cuna ${ }^{10}$. Lo cual, nos lleva a plantear el siguiente argumento respecto al débil rol que parecen desempeñar las clases altas en la generación de símbolos culturales en el actual sistema de la moda: a saber, considerado un hecho probado que la familia y las redes sociales continúan siendo necesarias para reproducir un sistema de clases estratificado, pues no olvidemos que el acceso a la alta sociedad es un pase restringido, es posible razonar que haya sido el propio sistema el que, necesitando para su desarrollo y perpetuación una apertura cada vez más continuada de nuevos mercados, haya preferido prescindir de unos pocos aunque acaudalados e influyentes consumidores como objeto de interés, para orientarse a un número de individuos potencialmente más rentable como son las clases medias y trabajadoras. Dejando, de esta manera, de ser los miembros de la alta sociedad los prescriptores más apropiados. Convirtiéndose, en palabras de Blumer (1969), en simples seguidores de tendencias. Por lo que habría sido la influencia de la moda de consumo sobre la moda de clase, lo que habría forzado a las clases altas y las élites a adoptar formas de vestir que se fundamentan en una indiferenciación estética simulada a partir de precios distintos ${ }^{11}$.

En cuanto a las clases medias o pequeño burguesas, debido a su complejidad y heterogeneidad, éstas han sido definidas, en oposición al proletariado y la alta burguesía, como un "grupo más amorfo, considerado a menudo como una categoría residual, pero que incluye a la mayoría de las profesiones liberales” (Bottomore, 1989, p. 191). Una fórmula que, ciertamente, aunque no se pueda extraer de ella un conocimiento absoluto, sí que al menos permite sobreentender razonablemente bien la necesidad que ha habido durante todo el siglo XX de incorporar el concepto de estatus al análisis de clases. Pues, no sólo transmite la tensión provocada por la introducción de una variedad de grupos en el abismo que se- 
paraba las principales clases marxistas, sino que, además, sirve para recordar que las clases medias no pueden ser consideradas un conjunto de entidades sociales e históricas a medio camino entre ricos y pobres. Ya que, al margen de su relativa y reciente aparición en el siglo XVIII, ni siquiera han llegado a todo el planeta a pesar de que su consolidación como clases de demanda global tuvo lugar con la Revolución Industrial, cuando dos sustanciales masas de productores y vendedores ${ }^{12}$ interrelacionaron con fines a inaugurar un importante número de centros comerciales Perrot (1981). Entre ellos: Le Bon Marché en 1852, Printemps en 1865 y Samaritaine en 1869. De ahí que un factor cardinal para su identificación en la estructura social haya sido siempre, y siga siendo, el consumo. En este sentido, hay que apuntar tres factores que determinaron su expansión: el primero, ya citado, es su enorme capacidad de demanda; el segundo, su función de control o contrarrevolución respecto a la impetuosa clase trabajadora; y el tercero, su rol como representante de los valores democráticos institucionalizados, Gaggi y Narduzzi (2006).

Ahora bien, tal como hemos planteado, aunque la multiplicidad de orígenes culturales y sociales impide conceptualizar las clases medias en clave homogénea, sus prácticas de consumo sí permiten observar coincidencias debido a que todas sus fracciones expresan la misma necesidad de optar por una estética intermedia con la que satisfacer sus deseos de ascenso, de confirmación y reconocimiento social. Una actitud de grupo que comporta, a nivel individual, tener que descartar toda apariencia démode o snob, aunque a veces, incursiones arriesgadas con fines a encontrar un reconocimiento y distinción como miembro de una fracción de clase emergente sean permitidas. De tal suerte que podemos afirmar que nos encontramos frente a una forma de consumo que, evitando cualquier tipo de experimentación estética como producto cultural y de libertad, contraviene, de algún modo, la radicalidad liberal que se le supone a una burguesía que ha sido capaz de deshacerse de las relaciones sociales tradicionales. No en vano, mientras Ortega nos define al buen burgués como un "ente incapaz de sacramentos artísticos, ciego y sordo a toda belleza pura" (2009, p. 14), Bourdieu nos advierte que su conservadurismo estético es afín al de las clases populares porque más que demandar una representación conforme a la realidad, a lo que aspira es a seguir reconociendo unos cánones de estilo que ya domina (2010). Y sin embargo, este último distingue tres fracciones pequeño-burguesas que califica como decadente, ejecutiva y nueva pequeña burguesía. De modo que, respecto a la primera fracción, la decadente, constituida básicamente por artesanos y pequeños comerciantes, Bourdieu observa que, tanto sus propiedades objetivas como subjetivas, se encuentran amenazadas por el desarrollo económico y cultural. Siendo este el motivo por el que sus elecciones son similares a las de los obreros, aunque no les sean impuestas por la necesidad en el mismo grado que a éstos. Es decir, son elecciones regresivas que se inclinan por la austeridad y la tradición al amparo de un ethos de trabajo, orden y rigor. La segunda fracción, la burguesía ejecutiva, es la representada por cuadros medios, en su mayoría autodidactas, que valoran las actividades que requieren buena voluntad y dedicación por el imperativo de la ascensión social. Su inclinación por una visión progresista del mundo les hace postergar ad infinitum el placer de un tiempo presente que nunca llega. Siendo ello la causa de que al final de su ciclo vital adopten posiciones conservadoras, tanto en el plano de la estética como en el de la ética. Finalmente, la tercera fracción, la nueva pequeña burguesía, marca el polo cultural de la clase media. Son en su mayoría individuos que, o bien 
no han obtenido del sistema escolar las titulaciones que les hubieran permitido reivindicar con éxito las posiciones establecidas que les prometía su posición social de origen, o bien no han obtenido de sus titulaciones todo lo que consideraban con derecho a esperar por referencia a un estado anterior de la relación entre las titulaciones y sus posiciones. Una dicotomía que se traduce, por un lado, en una expresión diferenciada de rechazos y preferencias éticas en función de los valores de origen, por lo que a lo divertido, lo artístico, lo refinado y lo distinguido es decir las virtudes que demanda la nueva pequeña burguesía, se le opondrá la preferencia de lo clásico y lo ponderado; y por otro, en una necesidad común por ajustar las ocupaciones a las ambiciones, más que las ambiciones a las ocupaciones. De ahí la proliferación de profesiones de presentación y representación: comercio, publicidad, relaciones públicas, moda, decoración, de servicios de asistencia médico social: sexólogos, dietéticos, consejeros conyugales, o de animación y producción cultural: animadores, educadores, realizadores, presentadores, y periodistas. Con lo que queda claro que serán los originarios de las clases superiores quienes, aún faltos de capital escolar, acaben realizando elecciones más parecidas a las de la burguesía.

Pero esto no es todo. Desde un enfoque realista ${ }^{13}$ Savage (1992) ha apuntado que la relevancia de las luchas por el estatus en las clases medias se debe a su configuración a partir de accesos diferentes a tres tipos de bienes, sean estos: propiedades, posiciones en jerarquías organizativas y bienes culturales o habitus y estilos de vida que refuerzan y perpetúan las estructuras de poder. De modo que, aunque los análisis de clases puedan concluir que la acentuación de la diversidad está produciendo una pérdida de la noción de equidistancia en la estructura social, y que la crisis de empleabilidad, las nuevas formas de trabajo, las desigualdades de renta, están homogeneizando la sociedad tanto por arriba como por abajo, ello no impide observar que las diferencias en consumo de moda continúan emergiendo. Pues, incluso cuando parecía que las clases medias se habían convertido "de facto en modelos cuasi-omnicomprensivos de referencia de una parte sustantiva de la sociedad" (Tezanos, 2009, p. 299), nuevos marcos estratificacionales internos no paraban de surgir. Es decir, aun aceptando que las clases medias pudieran "haber llegado a encontrar su punto crítico, paradójicamente, en su propia expansión desmedida, en su éxito como referente social" (Tezanos, 2009, p. 304), al ser la clase un concepto basado no sólo en la estructura social sino en la relación, más allá de que un tipo de consumidor de clase media prefiere mercancías a bajo coste, también los hay que prefieren bienes y servicios exclusivos, personalizados y con un elevado valor adicional. De ahí que podamos sustentar que el consumo de moda sigue diferenciado entre quien busca un tipo de producto de marca consolidada, es decir, arraigada en las alta esferas de la estructura social, y quien se arriesga con novedades que va a tener que transformar en símbolos de reconocimiento o estatus a base de capital cultural. Finalmente, en otro orden, frente a las nuevas clases medias como fenómeno relativamente tardío del proceso de industrialización, la celeridad con la que irrumpieron las clases trabajadoras en el primer período de la revolución industrial sólo se explica por la urgente necesidad de un elevado número de individuos durante la mecanización de los procesos de producción, Kerbo (1998). En este sentido, que dicho fenómeno se fundamenta en un doble proceso: la expulsión del campesinado de sus tierras y el crecimiento de la industria urbana, no impide reconocer que una parte de sus integrantes originarios también fueron artesanos que, ejerciendo un arte manual durante 
la época preindustrial, fueron obligados a intercambiar su racionalidad de mercado, base de su ética de trabajo, por la disciplina de fábrica. Bauman lo resume del siguiente modo:

El propósito de la cruzada moral era recrear, dentro de la fábrica y bajo la disciplina impuesta por los patrones, el compromiso pleno con el trabajo artesanal, la dedicación incondicional al mismo y el cumplimiento, en el mejor nivel posible, de las tareas impuestas (2005, p. 19).

En efecto, lo que realmente se puso en marcha durante dicho periodo fue una instrucción orientada a que el ser humano, en su calidad de obrero, dejara de pensar mientras realizaba tareas que no comprendía. Un ideal culminado con relativo éxito a mediados del siglo $\mathrm{XX}$, recordemos si no cómo fue naturalizada la inferioridad del trabajador manual frente al intelectual, que acabaría desmoronándose dos décadas más tarde debido a la incorporación de la mujer, los jóvenes, los inmigrantes y los nuevos titulados a una espacio laboral con una sucesiva falta de empleo. Siendo ello la causa principal de un entorno sociolaboral heterogéneo, de que el trabajador tradicional en trase en un estado de desconcierto cada vez mayor, Lacalle (2006). Una situación que no sólo provocó la fragmentación de las comunidades tradicionales sino también un debilitamiento en la dialéctica de clases. No obstante, del proceso de industrialización no sólo emerge una ética de renuncia a la libertad sino también una miríada de posibilidades con las que exteriorizar el malestar hacia el establishment moderno. Así, entre el dandi ${ }^{14}$ del siglo XVIII y los indies postmodernos, pasando por los mods de los sesenta o los punk de los setenta, todos y cada uno de los grupos y subgrupos contrarios a las normas y valores que el statu quo ha ido imponiendo han expresado su rechazo a través de indumentos como signos de diferenciación ideológica y social. Lo cual, no es de extrañar dada la analogía que aplica la burguesía entre cuerpo y alma, entre exterior e interior, como medio para valorar personas. Siendo ello causa suficiente para que podamos afirmar que quienes mejor han sabido teatralizar su propia existencia, aunque sólo sea para alejarse de su monotonía y condición, son aquellos que transitan por un umbral social de riesgo y contingencia (Entwistle, 2002) ${ }^{15}$. En este sentido, aunque en la actualidad la reconfiguración de la estructura competitiva y el posicionamiento de las economías emergentes han propiciado que la correlación entre formas de vestir y clases no sea tan clara como lo fue durante todo el siglo XIX y parte del XX, pues la oferta de inspiración urbana a coste reducido que comercializaron durante la década de los ochenta Christian Dior, Giorgio Armani o Calvin Klein posibilitó que una amplia franja de consumidores de clases medias y trabajadoras rompiera el tabú de que la moda sólo era para élites, lo cierto es que ello no demuestra que las clases hayan desaparecido. Es decir, si como señala Crompton, “...los factores que producen las diferentes expresiones de la conciencia social no están distribuidos de un modo aleatorio entre el conjunto de la población” (1997, p. 246), cabe reflexionar si aún existen modos de percibir diferenciados. Pues, mientras las mujeres de clases populares continúan utilizando menos lociones y cremas de cara que las mujeres de otras clases, así como perfumes y colonias, el consumo en barras de labios y contornos de ojo sí resulta similar porque, socialmente, esta es una zona del cuerpo que está institucionalizada ${ }^{16}$. Frente al embellecimiento total y continuo que practican las mujeres de otras clases, las mujeres trabajadoras actúan sólo para la ocasión. 
Aunque, a tenor de su incorporación al mundo laboral, dicha ocasión se haya convertido en cotidianidad debido a la obligación de recrear imágenes estereotipadas para el sector servicios. Una inflexión contraria a lo que Boltanski (1971) proponía en la década de los setenta cuando resaltaba la poca vigilancia y cuidado que recibían los cuerpos que funcionan como herramientas de trabajo. Pues como portador de prestigio y honor, al no poder ser controlado con total efectividad, el cuerpo se convierte en el signo más relevante del ser humano. En efecto, un ejemplo de análisis actual que corrobora las conclusiones de Bourdieu (1991) sobre las bases sociales del gusto es el de Magatti y De Benedittis (2006). En el mismo se descubre que a pesar de la percepción generalizada de bienestar individual que se ha disfrutado durante el último decenio, la relación entre trabajo y ahorro sigue expresándose a través del consumo de lo necesario. Pues, aunque la performatividad parece haber resquebrajado las jerarquías sociales, lo que hace creer que el estatus del que se disfruta es igual para todos, lo cierto es que las oportunidades de acción y los modelos de comportamiento aparentemente diversos continúan rígidos y estandarizados. Las clases trabajadoras perpetúan su mirada al futuro más que al presente porque su referente, la necesidad, obliga a administrar y controlar un gasto que puede significar una privación ulterior, Borràs (1998). Especialmente, en momentos de incertidumbre e inseguridad laboral como los que afrontan las sociedades postindustriales. Una realidad que los enfoques postmodernos han intentado ocultar afirmando que el consumo desaforado y hedonista de las clases populares, específicamente los más jóvenes era la prueba irrefutable de la ausencia de conflicto de intereses. Una presunción que ha resultado, si más no, inapropiada ante la persistencia de comportamientos auto-coercitivos, bien por motivos económicos, bien por motivos de incapacidad lectora y comprensiva de una simbología en constante mutación. Pues, "no existe herencia material que no sea a la vez una herencia cultural" (Bourdieu, 1991, p. 75). Con esto queda claro que las elecciones de lo sencillo alejadas de lo simbólico y lo estético continúan reapareciendo como forma explícita del gusto por lo funcional y la conformidad. Un posicionamiento estético incapaz de abandonar la realidad nada más que como excepción o expresión de lo extraordinario. De ahí el retorno de lo humano y lo reconocible frente a lo extraño y lo foráneo. La búsqueda de relaciones domésticas y de vecindad. De solidaridad. De obligación hacia el grupo y la familia. Y con ello, la confabulación contra los consumos ilegítimos y el resurgir de actores que “...no se comportan o deciden como átomos fuera de un contexto social, [aunque tampoco se adhieran] ... de modo servil a un guión escrito para ellos por una intersección particular de las categorías sociales que ocupan" (Granovetter ,1985, p. 487).

\section{La clase, la conciencia, el habitus}

De suerte que, según esto, para comprender una categoría social como el habitus, que permite explorar los significados que están en la base del comportamiento del consumidor, una teoría que puede aportar complementariedad a las contribuciones esenciales de Bourdieu puede ser la que desarrollan Douglas e Isherwood (1984) sobre la necesidad del ser humano de establecer una cierta coherencia y regularidad en el mundo que le rodea. Pues, 
en ella, a parte de afirmarse que los conceptos abstractos son sustituidos por objetos con fines a poder desarrollar un comportamiento racional, lo que implica su utilización para enmarcar, clasificar y representar experiencias humanas, vinculando el pasado, presente y futuro, así como lo social a lo individual y lo material a lo cultural, todas ellas funciones del habitus, se alude, primero, a que la racionalidad aplicada al consumo depende del grado de riqueza adquirido, no sólo material, lo cual obliga a ponerse en una correcta perspectiva desde la que poder evaluarse a sí mismo, considerando la distancia con respecto a la necesidad; segundo, a que cuando se practica un consumo en solitario, sea por caso comer sin compañía, inconscientemente se adoptan las mismas reglas y categorías que se utilizan en sociedad, habitus y estilo de vida. En este mismo sentido de necesidad de orden con el que poder establecer un mundo inteligible, Heller (1977), con anterioridad, ya había observado que si la capacidad de clasificar surge, en primera instancia, de una necesidad pragmática, una vez existe no se detiene en los límites del pragmatismo sino que, relativamente autónoma, se convierte en habilidad al servicio de la conquista teorética de la realidad. Una conclusión que permite introducir una relación causal e inversa con la que poder justificar que, en un contexto histórico, “... un individuo es un hombre que se halla en relación consciente con la genericidad y que ordena su vida cotidiana en base también a esta relación consciente -evidentemente en el seno de las condiciones y posibilidades dadas" (1977, p. 55). Lo que nos aboca, sin duda, a una noción de conciencia de clase como corolario de experiencias de privación relativa. Pues, lo esencial, no es el nivel de poder, ingresos o preeminencia social en general que podamos ostentar, sino el que retienen aquellos que uno ve como más próximos o iguales, Giner (1993). Pues bien, reivindicar, como hace Thompson (1989), una concepción de clase como relación y proceso, implica reconocer que existen formas de conciencia imperfectas o parciales que son auténticas expresiones de clase y de lucha de clase, válidas en sus circunstancias aun cuando sean erróneas desde el punto de vista de un desarrollo posterior (Meiksins, $1983)^{17}$. Implica, asimismo, aceptar que aunque la expresión completa de conciencia de clase sólo pueda emerger de una integración de las dimensiones subjetivas, intersubjetivas y objetivas de los procesos y estructuras de cambio social, lo que la precede es siempre una vivencia o experiencia de clase. Un habitus, en definitiva, en continua reestructuración por exigencias de una vida especulativa. De ahí que dicho autor resuelva que sólo tras haber experimentado la desigualdad en una sociedad estructurada, no sólo en relaciones de producción se pueda comenzar a identificar puntos de interés antagónicos con los que engendrar procesos de lucha que acaben por hacer descubrir que se forma parte de un grupo o clase. Entendiendo por dicho descubrimiento, lo que se conoce como conciencia de clase. He aquí porqué sitúa en una distinción heurística y no ontológica la clase y la conciencia de clase como últimas fases de un proceso real histórico, Estrella (2008). Una conclusión a la que se adelanta Merleau-Ponty (1975) cuando declara que basta haber nacido y existir para percibir la vida como difícil y coaccionada sin haberla elegido, pero que para poder llegar a visualizar la polarización del espacio social, antes se debe experimentar la vida de forma sincrónica a la de los demás. Sin duda, poner énfasis en el concepto de experiencia para la formación de clases, siendo el habitus un unificador de los diferentes ámbitos de toda experiencia, refuerza la posibilidad de establecer analogías que contemplen la sustitución de una categoría como el habitus por otra como la conciencia de clase. 
Pues el habitus, como ${ }^{18}$ conjunto de esquemas implantados en el seno familiar pero constantemente repuestos y reactualizados durante toda la trayectoria social, no sólo aparece como responsable del sentido en el que operan las relaciones de fuerza en los diferentes campos o espacios sociales sino que lo hace de las prácticas orientadas a un cambio social. Siendo este el motivo ${ }^{19}$ por el que, contraviniendo a Bourdieu (1984), nos resistimos a sobreestimar el habitus, más cercano a un inconsciente de clase que a una conciencia de clase. Ya que, tal como sostiene dicho autor, si es cierto que el "trabajo de categorización, es decir, de explicitación y de clasificación, se realiza sin cesar, en todo momento de la vida diaria,...” (1984, p. 211), que las respuestas a la reproducción social que exigen los nuevos nexos entre procesos económicos, políticos y culturales sean cada vez más aceleradas, véase si no el incremento de la discapacitación y re-capacitación para responder a las nuevas necesidades del mercado laboral, implica tener que debatir constantemente por una comprensión de un espacio-temporal que pone a prueba nuestra capacidad para enfrentarnos a las realidades desplegadas. Y es que, a pesar de que el habitus sea, no sólo una estructura estructurada sino una estructura estructurante, ello no parece indicar que las posibilidades de resistencia y cambio sean muy probables para los sujetos sociales. Una situación a la que, por otra parte, es difícil no reaccionar con un alto grado de estrés por el malestar, la ansiedad, la inquietud o la expectación que genera debido a los cambios culturales, políticos, tecnológicos y relacionales ${ }^{20}$. Una perspectiva la nuestra que nos obliga a justificar argumentando que es suficiente con ser consciente de uno de los dos tipos de relaciones que comprometen una clase como relación, sean estas, por un lado, las relaciones existentes entre clases, y por otro, las relaciones existentes entre los miembros de una misma clase, para no negarnos una conciencia de clase aunque sea parcial. Pues ésta, sólo responde a opciones bajo presiones históricamente inteligibles.

En resumen, considerando el habitus como un “...principio generador y unificador que retraduce las características intrínsecas y relacionales de una posición en un estilo de vida unitario, es decir un conjunto unitario de elección de personas, de bienes y de prácticas" (Bourdieu, 2002, p. 19), retenemos que toda aspiración a un nuevo estilo de vida conlleva, de forma implícita, no sólo una previa conciencia de habitus de clase sino, como resultado, una conciencia de clase desde la que conectar o separarse de otra clase ${ }^{21}$. De ahí la necesidad de subrayar el constante ajuste a la posición social en función de las disposiciones que se van adquiriendo mientras ostentamos dicha posición. Pues, es esta, la posición que ocupamos en dicho espacio, la que en interacción con otras posiciones va a acabar orientando nuestro comportamiento (Bourdieu, 2002). En este caso, nuestro comportamiento consumidor.

\section{A modo de conclusión}

En este escrito la intención se ha centrado en resaltar la vigencia del concepto de clase como indicador social a pesar de las transformaciones en los procesos de trabajo y la fragmentación de los estilos de vida. Pues, más allá de la retórica postmodernista, lo cierto es que, como señala Alonso (2004), no estamos en una sociedad del fin del trabajo, ni mucho menos, sino en una sociedad del trabajo sin fin. Una verdad que alude a la muy 
discutible pérdida de la importancia del término clase social como expresión de actitudes y comportamientos grupales. Ahora bien, en sociedades contemporáneas, siendo de vital importancia el capital económico, no lo es menos el capital cultural, social y simbólico. Pues todos ellos conforman fuentes de poder. De ahí que el concepto de clase puesto de relieve haya sido aquel que se separa del reduccionismo economicista aplicado por el marxismo al mundo social. En este sentido, la inflexión de Bourdieu representa el mayor esfuerzo llevado a cabo por romper con la versión teórica de la clase original marxista. Pues reconoce a los agentes sociales como individuos que se sitúan en el espacio social multidimensional según el tipo, la composición y volumen de sus múltiples capitales. Una forma de concebir la clase como categorías de agentes que pueden llegar a tener intereses afines en un campo concreto. Con ello, se evita tanto el determinismo económico como el privilegio de lo económico sobre otros capitales. $Y$ es en este sentido que parece que para el autor francés los seres humanos sean más productores de símbolos que productores de bienes. De ahí la relación biunívoca entre clase y estatus. Por otra parte, también hemos querido significar que aunque la nueva pequeña burguesía haya facilitado la transmisión de símbolos y valores a los estratos más desaventajados de la estructura social, creando así una especie de des-diferenciación, lo cierto es que las oposiciones subjetivas continúan estando presentes. De tal manera que, aunque haya habido en ciertos momentos una mínima distancia objetiva, la distancia subjetiva siempre se ha mantenido. Pues tal como recuerda Bourdieu: "las diferencias percibidas no son las diferencias objetivas, y la vecindad social, lugar de la última diferencia, tiene todas las posibilidades de ser también el punto de mayor tensión" (2007, p. 221).

Por último, también hemos señalado, en un intento por evitar la parte más funcionalista y reproductiva de la teoría de la distinción, que la categoría de habitus puede ser interpretada como una especie de consciencia de clase, porque como sentido práctico de lo que hay que hacer en una situación determinada, remite a experiencias de clase en las que la consciencia, aunque parcial, suele estar presente como relación, bien entre clases, bien entre los miembros de una misma clase. Es decir, en el acto de consumo de moda existe una dimensión creativa que consiste en crear sentido y significados más allá de la simple reproducción de gustos. De manera que la ambigüedad a la que está sujeta la moda no sólo permite la reproducción sino la resistencia y reconstrucción de habitus.

\section{Notas}

1. Mientras la agencia de cruceros Royal Caribbean afirma que el contacto del hombre con el mar es un ritual mágico porque "Carecemos de aletas y branquias y aun así, no podemos dejar de mirarlo ni de tocarlo", Ikea anuncia sus productos para el hogar postula do que "Tenéis derecho a dormir tranquilos" sin hacer referencia a los mismos. (http://www. tvanuncios.com/) (12-10-2011).

2. Socialidad e identifiación son términos que remiten a un ideal de sociedad finiquitada. Son utilizados por Ibáñez en la Introducción de la obra de Mafessoli "El tiempo de las tribus" (1990: 15). 
3. Aunque los investigadores del paradigma del omnivorismo cultural se desarrolla bajo la tesis de que una nueva relación entre estratificación social y consumo cultural ha aparecido, y que esta relación se opone a las tesis individualistas y a la homología entre consumo y clases sociales, otorga a la clase trabajadora una simpleza, materialidad y naturalidad que no tiene. En este sentido véase, para una introducción general, Fernández y Heikkilä (2010), y para una comprensión de estos análisis, Peterson (1996; 2005), Sulli van y Katz (2007), Chang y Goldthorpe (2007).

4. En los años ochenta la incorporación de nuevas tecnologías y formas de gestión empresarial permiten generar discursos sobre personalización e individualización del consumo de moda que esconden una intensificación masiva de producciones de indumentos (Véase Joan Jiménez Gómez, La fascinación por la moda como expresión de libertad, RES nº 16, segundo semestre 2011).

5. Bourdieu (2010) hace notar que desde la aparición de la fotografía a ésta se le ha otorgado una patente de realismo que insta a creer que las imágenes creadas conforme reglas sociales son verdades objetivas. En este sentido, la fotografía se habría convertido en un patrón de realismo que convierte en realidad una visión del mundo inventada.

6. Los productos de la actividad humana que son socialmente designados como bienes simbólicos sólo existen para quienes poseen los medios de expropiarlos mediante el desciframiento del código históricamente constituido (Bourdieu, 2010).

7. Véase en Busquet $(1998 ; 1999 ; 2005)$ una posición contraria a la aquí expresada.

8. Las tendencias sociales de los últimos años del siglo XX señalaban que en España el $70 \%$ de los trabajadores manuales se consideraba "clase media" y sólo un $21,8 \%$ con clase trabajadora, obrera o proletaria (Tezanos, 2009).

9. La razón de que los artistas puedan ser equiparados a las clases altas como individuos capaces de distanciarse de la cotidianidad, remite a la relativa emancipación conseguida durante el siglo XV respecto al campo económico y político. De ahí que su función, desde entonces, sea recibida de la estructura del campo intelectual (Bourdieu, 2010).

10. Janer (2003) afirma que en España existen 35 grandes empresas que están en manos de las mismas familias desde hace casi 100 años, haciendo referencia a nombres como Ybarra, Rato, Botín, Alierta, Cortina, Entrecanales, Koplowitz, Oriol, etc.

11. Recordemos que la firma sueca $\mathrm{H} \& \mathrm{M}$, con 2.200 tiendas repartidas por 40 países, según su web, ha colaborado con diseñadores de prestigio como Karl Lagerfeld en 2004, Stella McCartney en 2005, Viktor \& Rolf en 2006, Roberto Cavalli en 2007, Comme des Garçons en 2008, Matthew Williamson, Jimmy Choo y Sonia Rykiel en 2009 y Lanvin en 2010.

12. Aunque el concepto clase media asociado a la política pueda descubrirse en alusiones de Aristóteles (2007) a la idea de virtud como un medio entre extremos.

13. Un enfoque realista se caracteriza por elegir como centro de atención empírica los procesos de formación de clase más que las descripciones de la estructura de clases (véase en este sentido Crompton, 1997).

14. El dandi, contrariamente a lo que suele pensarse, es un rebelde. Es la personificación de la no moda. Un romántico que se rebela contra la noción de "bien" que establece la sociedad. Y su rebeldía, que se traduce no en acción sino en estética, tiene por objeto denunciar que siguiendo las normas uno nunca acaba por sentirse satisfecho plenamente. 
15. La inclinación de Bourdieu por resaltar un único modelo de difusión de moda, el llamado trickle-down, ha sido criticada por resultar demasiado homogénea y conformista como resultado de la censura institucional o censura de la doxa, ya que no se aprecia resistencia alguna por parte de los agentes.

16. Respecto a ello remitimos al estudio Scanner 2008-9 sobre perfumes y cosmética femenina presentado por Hachette Filipacchi (10-11-2011) en C:IUserslusuario|Desktopl06_ perfumes_y_cosmetic.pdf

17. Para una interpretación menos economicista y más centrada en los fenómenos culturales de la obra de Marx, véase Williams (2008) y Thompson, E. P. (1979).

18. En este sentido Beriain llegará a afirmar que Bourdieu sustituye el concepto de conciencia de clase por el de habitus de clase en su triple ruptura con el análisis tradicional de las clases sociales (1996: 365).

19. En un sentido similar, entendiendo el habitus como una especie de conciencia de clase controlada, se expresa Sergio Miceli (2005).

20. Recordemos que Bourdieu fórmula que "los pequeños-burgueses se ven continuamente enfrentados a unas alternativas éticas, estéticas o politicas, y por tanto obligados a llevar al orden de la conciencia y de las elecciones estratégicas las operaciones más ordinarias de la existencia" (1991: 348), y que es G. H. Mead quien afirma que "La conciencia es funcional, no sustantiva" (1973: 147).

21. Para una mayor comprensión de la interrelación entre habitus y estilo de vida véase el análisis de Callejo (2004).

\section{Referencias bibliográficas}

Alonso, L. E. (2004). El trabajo sin fin, en Página Abierta no 151, septiembre Alonso, L.E. (2005) La era del consumo, Madrid: Siglo XXI.

Aristóteles. (2007). La Política, Madrid: Espasa-Calpe.

Baltzell, E. D. (2009). Philadelphia Gentleman: The Making of a National Upper Class, New Jersey: Transaction Publishers.

Bauman, Z. (2005). L'obra d'art a l'època de la seva reproductibilitat técnica, Barcelona: Edicions 62.

Beriain, J. (1996). La integración en las sociedades modernas, Barcelona: Anthropos Blumer, H. (1969) Fashion: From Class Differentiation to Collective Selection, pp. 275-291, en The Sociological Quarterly, vol. 10 no 3 (University of California, Berkeley).

Boltanski, L. (1971). Les Usages Sociaux du Corps, pp.205-233, en Les Annales, Borràs, V. (1998) El consumo, un análisis sociológico, Barcelona: Cedecs Bottomore, T.B. (1989) Introducción a la sociología, Barcelona: Ediciones 62 Bourdieu, P. (1984) Sociología y cultura, México: Grijalbo.

Bourdieu, P. (1991). La distinción, Madrid: Taurus.

Bourdieu, P. (2000). Cosas dichas, Barcelona: Gedisa.

Bourdieu, P. (2001). Poder, derecho y clases sociales, Bilbao: Desclée.

Bourdieu, P. (2002a). Razones prácticas, Barcelona: Anagrama. 
Bourdieu, P. (2002b). Condición de clase y posición de clase, Revista Colombiana de Sociología, Vol. VII No 1, pp. 119-141.

Bourdieu, P. (2007). El sentido práctico, Buenos Aires: Siglo XXI.

Bourdieu, P. (2010). El sentido social del gusto, Buenos Aires: Siglo XXI Busquet, J. (1998) El sublim i el vulgar, Barcelona: Proa.

Busquet, J. (1999). Crítica a la distinción cultural, Revista Catalana de Sociología, 10, pp.75102.

Busquet, J. (2005). Els escenaris de la cultura, Barcelona: Trípodos Caínzos, Miguel A. (1990) Explotación, dominación y estructura de clase, Revista Política y Sociedad, 5 (pp.89-105), Madrid.

Callejo, J. (2004). La práctica del consumo en Bourdieu: contra el formalismo y el populismo, en Las herramientas del sociólogo, pp.185-213, Madrid: Fundamentos.

Chan, T.W. (2010). Social Status and Cultural Consumption, University of Oxford Chan, T.W. y Goldthorpe, J. H. (2007) Social stratification and cultural consumption: The visual arts in England, Poetics, 35, pp.168-190.

Crompton, R. (1997). Clase y estratificación, Madrid: Tecnos.

De Botton, A. (2004). Ansiedad por el estatus, Madrid: Taurus.

Douglas, M. y Isherwood, B. (1984). Il mondo delle cose, Bologna: Il Mulino Entwistle, J. (2002) El cuerpo y la moda, Barcelona: Paidós.

Estrella, A. (2008). La clase social como vivencia: el modelo de E.P. Thompson y la dicotomía sujeto-objeto, no 10 de abril, en http://oolhodahistoria.org/artigos/RE SENHAS-clasesocial-como-vivencia-alejandro-gonzalez.pdf (27-10-2011) Fernández C.J. \& Heikkilä, R. (2011) El debate sobre el omnivorismo cultural. Una aproximación a nuevas tendencias en Sociología del Consumo, Revista internacional de Sociología RIS (online), vol. XX.

Gaggi, M. y Narduzzi, E. (2006). El fin de la clase media, Madrid: Ediciones Lengua de Trapo. Giddens, A. (2009). Sociology, $6^{\text {th edition }}$, Cambridge: Polity Press.

Giner, S.(1993). Sociología, Barcelona: Ediciones 62.

Granovetter, M. (1985). Economic action and social structure: the problem of embeddedness, en American Journal of Sociology, 91 (3), 481-510, Chicago: The University of Chicago press.

Hegel, G.W.F. (1997). Introducción a la estética, Barcelona: Nexos-Península Heller, A. (1977) Sociología de la vida cotidiana, Barcelona: Ediciones Península Janer, M. (2003) Todo queda en familia, Madrid: La Esfera de los Libros Jiménez Gómez, J. (2011) La fascinación por la moda como expresión de libertad, RES no 16 , segundo semestre.

Kerbo, H. R. (1998). Estratificación social y desigualdad, Madrid: McGraw-Hill Lacalle, D. (2006) La clase obrera en España, España: El Viejo Topo Maffesoli, M. (1990) El tiempo de las tribus. El declive del individualismo en la sociedad de masas, Barcelona: Icaria.

Magatti, M. y De Benedittis, M. (2006). I nuovi ceti popolari, Milano: Feltrinelli Marx, K. (2010a) Miseria de la filosofía, Ediciones en Lenguas Extranjeras, Moscú, s/f. Marxists Internet Archive.

Marx, K. (2010b). El capital, Marx, pp. 81-393, Madrid: El país Mead, G.H. (1973) Espíritu, persona y sociedad, Barcelona: Paidós Básica Meiksins, E. (1983) El concepto de clase en E. P. Thompson, en Cuadernos Políticos, no 36, pp.87-105, n 36, México.

Merleau-Ponty, M. (1975). Fenomenología de la percepción, Barcelona: Península Miceli, S. (2005) Introduçao: a força do sentido, en Pierre Bourdieu, $A$ economia das trocas 
simbólicas, 6a ${ }^{a}$ edic., pp. VII, São Paulo: Editora Perspectiva Ortega y Gasset. (2009) La deshumanización del arte, Madrid: Revista de Occidente en Alianza Editorial.

Pahl, R. E. (1991). Divisiones del trabajo, Madrid: Ministerio del Trabajo y la Seguridad Social. Pakulski, J. y Waters, M. (1996). The Death of Class, London: Sage Publications Ltd. Perrot, Ph. (1981) Les dessus et les dessous de la bourgeoisie, Paris: Fayard Peterson, R.A. (2005) Problems in comparative research: The example of omnivorousness, Poetics 33, pp. 257-282. Peterson, R.A. y Kern, R. M. (1996). Changing Highbrow Taste: From Snob to Omnivore, American Sociological Review, Vol. 61 No. 5, pp.900-907 Savage, M., Barlow, J., Dickens, A., Fielding, T. (1992) Property, Bureaucracy and culture: Middle Class Formation in Contemporary Britain, London: Routledge Sullivan, O. y Katz-Gerro, T. (2007) The Omnivore Thesis Revisited: Voracious Cultural Consumers, European Sociological Review, vol. 23, no 2, pp.123-137 Tezanos, J.F. (2009) La sociedad dividida, Madrid: Biblioteca nueva Thompson, E. P. (1979) Tradición, revuelta y consciencia de clase, Barcelona: Editorial Crítica.

Thompson, E. P. (1989). La formación de la clase obrera en Inglaterra, Barcelona: Editorial Crítica.

Weber, M. (1984). Economía y sociedad, México: Fondo de Cultura Económica.

Williams R. (2008). Historia y cultura común, Madrid: Catarata.

\begin{abstract}
The debate on the ineffectiveness of the concept of class as a category of sociological analysis, mentioned in the writings of Ray E. Pahl in Divisiones del Trabajo and Jan Pakulski and Malcom Waters The Death of Class; in a negative way, Bourdieu's (2010) theory of distinction, alluding to that it is based on a relationship between class, formation of taste and consumption, overcome by social fragmentation and globalization. In this sense, we highlight Coulangeon and Lemel in Social Status and Cultural Consumption of the year 2010. This paper counters that, even in highly developed and democratic societies, individualized and omnivorous consumptions are observed, these are developed from symbolic differentiations, reference groups, occupations and income levels. Because it belongs to a social class, it will be a key factor for the purchase of fashion. However, with respect to the habitus, it is overestimated as a class unconscious, as well as a structuring structure, induced to think that consumption practices are poorly intelligible. Hence the relevance of considering it as a class consciousness.
\end{abstract}

Keywords: sociology - consumption - status - distinction - omnivore - social class - habitus - class consciousness - distinction theory - societies.

Resumo: O debate sobre a ineficácia do conceito de classe como categoria de análise sociológica, mencionado nos escritos de Ray E. Pahl em Divisiones del Trabajo e em The Death of Class de Jan Pakulski e Malcolm Waters; de forma negativa, a teoria da distinção de Bourdieu (2010), aludindo a que se baseia em uma relação entre classe, formação do gosto e consumo, superada pela fragmentação social e pela globalização. Nesse sentido, destacamos Coulangeon e Lemel em Status Social e Consumo Cultural do ano 2010. Este 
trabalho contrapõe que, mesmo em sociedades altamente desenvolvidas e democráticas, observam-se consumos individualizados e onívoros, estes se desenvolvem a partir de diferenciações simbólicas, grupos de referência, ocupações e níveis de renda. Por pertencer a uma classe social, será um fator chave para a compra de moda. Porém, no que diz respeito ao habitus, ele é superestimado como inconsciente de classe, assim como uma estrutura estruturante, induz a pensar que as práticas de consumo são pouco inteligíveis. Daí a relevância de considerá-la uma consciência de classe.

Palavras chave: sociologia - consumo - status - distinção - onívoro - classe social - habitus - consciência de classe - teoria da distinção - sociedades.

[Las traducciones de los abstracts fueron supervisadas por el autor de cada artículo] 